\title{
Rational diagnosis and treatment in unclassified arthritis: how clinical data may guide requests for Lyme serology and antibiotic treatment
}

\author{
Ineke Blaauw, Ben Dijkmans, Paul Bouma, Sjef van der Linden
}

\author{
Department of \\ Internal Medicine, \\ Division of \\ Rheumatology, \\ University Hospital \\ Maastricht and \\ University of Limburg, \\ Maastricht, The \\ Netherlands \\ A A M Blaauw \\ Sj van der Linden \\ Department of \\ Rheumatology, \\ University Hospital \\ Leiden, Leiden, The \\ Netherlands \\ B A C Dijkmans \\ Department of \\ Neurology, University \\ Hospital Leiden, \\ Leiden, The \\ Netherlands \\ P A D Bouma \\ Correspondence to: \\ Dr A A M Blaauw, \\ University Hospital \\ Maastricht, \\ PO Box 5800, \\ NL-6202-AZ Maastricht \\ The Netherlands. \\ Accepted for publication \\ 30 October 1992
}

\begin{abstract}
To improve the appropriateness and efficiency of diagnostic serological tests and subsequent antibiotic treatment, clinical data from 102 patients with unclassified arthritis were analysed to investigate whether the presence of positive IgG antibodies to Borrelia burgdorferi could be predicted.

The clinical data were blindly ranked from 1 to 4 (1, Lyme arthritis unlikely; 4, Lyme arthritis very likely). Antibodies to $B$ burgdorferi were positive in nine of 102 patients $(9 \%)$. Six of $15(40 \%)$ patients with rank numbers 3 and 4 were positive for antibodies to $B$ burgdorferi, in contrast with only three of $87(3 \%)$ patients with rank numbers 1 and 2 .

The likelihood ratio of positive Lyme serology for patients ranked 3 and 4 was $12 \cdot 0$, for patients ranked 2 to $4,4 \cdot 5$, and for patients with arthritis of the knee, 3.0. These likelihood ratios were associated with a post-test probability of 55,30 , and $20 \%$ respectively.

The clinical history in patients with unclassified arthritis can largely predict the presence of antibodies to $B$ burgdorferi. The absolute value of a likelihood ratio can be a contributing factor in deciding to request tests for antibodies to $B$ burgdorferi in patients with unclassified arthritis.
\end{abstract}

(Ann Rheum Dis 1993; 52: 206-210)

In Lyme borreliosis, a disorder caused by the tick borne spirochaete Borrelia burgdorferi, the

Table 1 Criteria for ranking patients with arthritis (arthritis with or without a history of an erythematous skin lesion, tick bite, neurological, or cardiac disorders) according to their probability of Lyme borreliosis. Ranking based on the clinical history and physical examination of the individual patient

\begin{tabular}{lll}
\hline Rank & Definition & Condition \\
\hline 4 & Very likely to be Lyme arthritis & $\begin{array}{l}\text { Erythematous skin lesion or ACA* and tick } \\
\text { bite; erythematous skin lesion or ACA and } \\
\text { neurological disorders } \dagger \text {; erythematous skin } \\
\text { lesion or ACA and cardiac disorders;; tick } \\
\text { bite and neurological disorders; tick bite } \\
\text { and cardiac disorders; neurological and } \\
\text { cardiac disorders }\end{array}$ \\
3 & Likely to be Lyme arthritis & $\begin{array}{l}\text { Erythematous skin lesion; tick bite; } \\
\text { neurological disorders; cardiac disorders; } \\
\text { ACA; or recurrent arthritis of the knee }\end{array}$ \\
1 & $\begin{array}{l}\text { Arthritis of the knee } \\
\text { Monarthritis or oligoarthritis of other joints; } \\
\text { polyarthritis }\end{array}$ \\
\hline
\end{tabular}

*ACA=acrodermatitis chronica atrophiçans.

†For example, facial palsy, Bannwarth's syndrome.

†For example, atrioventricular conduction defects. musculoskeletal system is often affected. ${ }^{1}$ Common symptoms of this disease are migratory pain in the joints, tendons, and bursae, brief arthritis attacks, and in later stages prolonged arthritis attacks, chronic arthritis, and peripheral enthesopathy. ${ }^{2}$ The musculoskeletal symptoms may occur without preceding erythema migrans, cardiac, or neurological symptoms. ${ }^{1}$

Lyme arthritis, though not a common cause of arthritis (at least not in the Netherlands), should be considered in the differential diagnosis because antibiotic treatment is usually effective. ${ }^{3-5}$ Owing to a large number of false positive results, and other reasons including economic aspects, however, it seems inappropriate to test for antibodies to $B$ burgdorferi in all patients with unclassified arthritis. ${ }^{6}$ It is important to know in which subset of patients with arthritis the test should preferably be ordered to obtain clinically meaningful results.

The presence of characteristic signs or symptoms of Lyme borreliosis in the clinical history and physical examination of patients with arthritis should guide rheumatologists in the decision to request a test for antibodies to $B$ burgdorferi.

The purpose of this study was to investigate how we could estimate the presence of antibodies to $B$ burgdorferi from clinical data in patients with arthritis, and how this influences the decision to prescribe antibiotic treatment.

\section{Patients and methods}

Antibodies to $B$ burgdorferi were determined in all patients with arthritis from the outpatient department of rheumatology of the University Hospital of Leiden - that is, those patients in whom a firm rheumatic diagnosis could not be made on their first visit or after several visits. Specifically, these patients did not fulfil criteria for rheumatoid arthritis, osteoarthritis, gout, systemic lupus erythematosus, chondrocalcinosis, reactive arthritis, or seronegative spondyloarthropathy. Based only on the clinical history and physical examination of the individual patient, all patients were given a rank number from 1 to 4 , where 1 is considered unlikely and 4 very likely to be Lyme arthritis. The criteria for these rank numbers were set for this particular study (table 1). These criteria were based on published work about the natural history of the disease and our own experience of patients with Lyme 
arthritis. ${ }^{2578}$ The surveillance case definition for Lyme disease as developed by the Centers for Disease Control in the USA was also incorporated. ${ }^{9}$ Patients were given a rank number without knowledge of the serological results. We expected positive serological results mainly in patients ranked 2 to 4 . Seronegativity was not expected among patients with arthritis due to Lyme borreliosis, which is a late stage of Lyme disease. ${ }^{12} 7$

\section{SEROLOGY}

IgG antibodies to $B$ burgdorferi were determined by an enzyme linked immunosorben assay (ELISA) as described elsewhere by the National Institute of Public Health and Environmental Protection (Bilthoven, the Netherlands). ${ }^{10} 11$ The ELISA values are expressed as optical density ratios. An optical density ratio of two is three standard deviations above the mean of 35 serum samples from blood donors. An optical density ratio equal to or greater than two is considered positive. If a positive test result was obtained the Treponema pallidum haemagglutination assay was performed to exclude false positivity due to antibodies to $T$ pallidum. Serum samples from this institute were also tested at the laboratory of the department of microbiology of the University of Limburg at Maastricht, the Netherlands (Dr M K E Nohlmans) in accordance with a Dutch Lyme study group. There was good agreement between laboratories $(r=0.94 ; \mathrm{p}<0.001)$ (unpublished results). In the absence of a reference or 'gold'

Table 2 Rank numbers of 102 patients and the proportion of patients positive for antibodies to Borrelia burgdorferi within each category

\begin{tabular}{ll}
\hline & $\begin{array}{l}\text { No (\%) of patients with positive } \\
\text { IgG serology }\end{array}$ \\
\hline Rank 4 $(\mathrm{n}=2)$ & $2(100)$ \\
Rank 3 $(\mathrm{n}=13)$ & $4(31)$ \\
Rank 2 $(\mathrm{n}=30)$ & $1(3)$ \\
Rank 1 $(\mathrm{n}=57)$ & $2(4)$ \\
Total 102 & $9(9)$ \\
\hline
\end{tabular}

Table 3 Clinical symptoms and antibodies to Borrelia burgdorferi of patients ranked 3 and 4

\begin{tabular}{|c|c|c|c|}
\hline Patient No & Clinical symptoms & Rank & Antibodies \\
\hline 1 & $\begin{array}{l}1986 \text { tick bite } \\
1988 \text { severe stiff neck } \\
1989 \text { severe stiff neck } \\
1986-90 \text { arthralgia } \\
1990 \text { frank arthritis of the knee and ankle }\end{array}$ & 4 & Positive \\
\hline 2 & 1989 tick bite with erythematous skin lesion & & \\
\hline 3 & $\begin{array}{l}1990 \text { arthritis of the knee } \\
1990 \text { facial palsy and polyarthritis }\end{array}$ & $\begin{array}{l}4 \\
3\end{array}$ & $\begin{array}{l}\text { Positive } \\
\text { Negative }\end{array}$ \\
\hline $\begin{array}{l}4 \\
5\end{array}$ & $\begin{array}{l}1989 \text { bite, pericarditis, and recurrent arthritis } \\
1985 \text { erythema migrans (confirmed by doctor) } \\
1986 \text { arthritis of the knee }\end{array}$ & 3 & Negative \\
\hline & 1990 arthritis of the knee & 3 & Negative \\
\hline 6 & $\begin{array}{l}1988 \text { facial palsy and arthritis of the ankle } \\
1990 \text { arthritis of the ankle }\end{array}$ & 3 & Negative \\
\hline 7 & $\begin{array}{l}1991 \text { polyarthritis and acrodermatitis chronica } \\
\text { atrophicans }\end{array}$ & 3 & Positive \\
\hline $\begin{array}{l}8 \\
9\end{array}$ & $\begin{array}{l}1990 \text { tick bite and arthritis of the knee } \\
1987 \text { tick bite }\end{array}$ & 3 & Positive \\
\hline $\begin{array}{l}10 \\
11 \\
12 \\
13 \\
14 \\
15\end{array}$ & $\begin{array}{l}1989 \text { recurrent arthritis of the knee } \\
1987-9 \text { recurrent arthritis of the knee } \\
1987-90 \text { recurrent arthritis of the knee } \\
1988-9 \text { recurrent arthritis of the knee } \\
1987-90 \text { recurrent arthritis of the knee } \\
1989 \text { recurrent arthritis of the knee } \\
1986-9 \text { recurrent arthritis of the knee }\end{array}$ & $\begin{array}{l}3 \\
3 \\
3 \\
3 \\
3 \\
3 \\
3\end{array}$ & $\begin{array}{l}\text { Positive } \\
\text { Negative } \\
\text { Negative } \\
\text { Positive } \\
\text { Negative } \\
\text { Negative } \\
\text { Negative }\end{array}$ \\
\hline
\end{tabular}

standard, an exchange of serum samples between the department of microbiology at Maastricht and the department of zoology, University of Neuchâtel, Switzerland (Dr L Gern) resulted in good agreement between the two laboratories $(\mathrm{r}=0 \cdot 68 ; \mathrm{p}=0 \cdot 001) .^{12}$

\section{DIAGNOSTIC TOOLS}

Sensitivity, specificity, positive predictive values, and likelihood ratios (percentage true positive to percentage false positive) were calculated for patients in ranks 3 and 4, ranks 2 to 4 , and for all patients who presented with arthritis of the knee. ${ }^{13}$

\section{STATISTICAL ANALYSIS}

For categorical data the $\chi^{2}$ test was used to test for significant differences between proportions. A value of $p \leqslant 0.05$ was considered statistically significant.

\section{Results}

From January 1989 to April 1991 IgG antibodies to $B$ burgdorferi were determined in 102 patients with unclassified arthritis. The mean age of these patients was 42.8 years (ranging from 14 to 75 years). The male to female ratio was $1 \cdot 1: 1 \cdot 0$.

Table 2 gives rank numbers and the proportion of patients positive for antibodies to $B$ burgdorferi. Nine patients were positive for antibodies to $B$ burgdorferi $(9 \%)$. Table 3 gives the clinical symptoms of the 15 patients with rank numbers 3 and 4 . Six of these 15 patients $(40 \%)$ were positive for antibodies to $B$ burgdorferi. Eight of these 15 patients had recurrent arthritis of the knee, and two of the 8 were positive for antibodies to $B$ burgdorfer $(25 \%)$ (table 3$)$. Of the 30 patients with nonrecurrent arthritis of the knee and ranked 2 , only one $(3 \%)$ was positive for antibodies to $B$ burgdorferi. The two patients ranked $1(4 \%)$ who were positive for antibodies to $B$ burgdorferi had symmetrical polyarthritis and arthritis of the metatarsal joints of one foot.

Patients with rank numbers 3 and 4 were positive for antibodies to $B$ burgdorferi significantly more often than patients with rank numbers 1 and $2(p<0.001)$. Patients with recurrent arthritis of the knee were positive for antibodies to $B$ burgdorferi significantly more often than patients who had their first attack of arthritis of the knee $(p<0.05)$.

The sensitivity was moderate for patients ranked 3 and $4(40 \%)$ (table 4$)$. The positive predictive value was $66 \%$.

The likelihood ratios calculated for each cutoff level were applied in a nomogram adapted from Fagan. ${ }^{14}$ The pretest probability for positive Lyme serology in this group (patients with unclassified arthritis) was 9\% (table 2). If Lyme serology was requested for patients with rank number 3 or 4 , the post-test probability of Lyme borreliosis increased to nearly $55 \%$. If patients with arthritis of the knee (rank 2) are added to this group, the posttest probability decreased to $30 \%$ (figure). 
Knees are the most affected joints in Lyme borreliosis. $^{257}$ Therefore we placed all the patients with a first attack of arthritis of the knee and with recurrent arthritis of the knee in one group (41 patients from ranks 2 to 4 ). After this we calculated the sensitivity $(14 \%)$, the specificity $(95 \%)$, the positive predictive

Table 4 Sensitivities, specificities, positive predictive values, and likelihood ratios of clinical evidence as a diagnostic test for Lyme arthritis at different levels of clinical suspicion of disease. Positive Lyme serology among 102 patients with unclassified arthritis is taken as the gold standard for the disease

\begin{tabular}{llllll}
\hline & $\begin{array}{l}\text { Positive } \\
\text { serology }\end{array}$ & $\begin{array}{l}\text { Sensitivity } \\
(\%)\end{array}$ & $\begin{array}{l}\text { Specificity } \\
(\%)\end{array}$ & $\begin{array}{l}\text { Positive } \\
\text { predictive } \\
\text { value } \\
(\%)\end{array}$ & $\begin{array}{l}\text { Likelihood } \\
\text { ratio }\end{array}$ \\
\hline Ranks 3 and 4 $(\mathrm{n}=15)$ & 6 & 40 & 96 & 66 & $12 \cdot 0$ \\
$\begin{array}{l}\text { Ranks 2, 3, and 4 }(\mathrm{n}=45) \\
\text { Arthritis of } \\
\text { the knee (n=41) }\end{array}$ & 7 & 15 & 96 & 77 & $4 \cdot 5$ \\
\hline
\end{tabular}

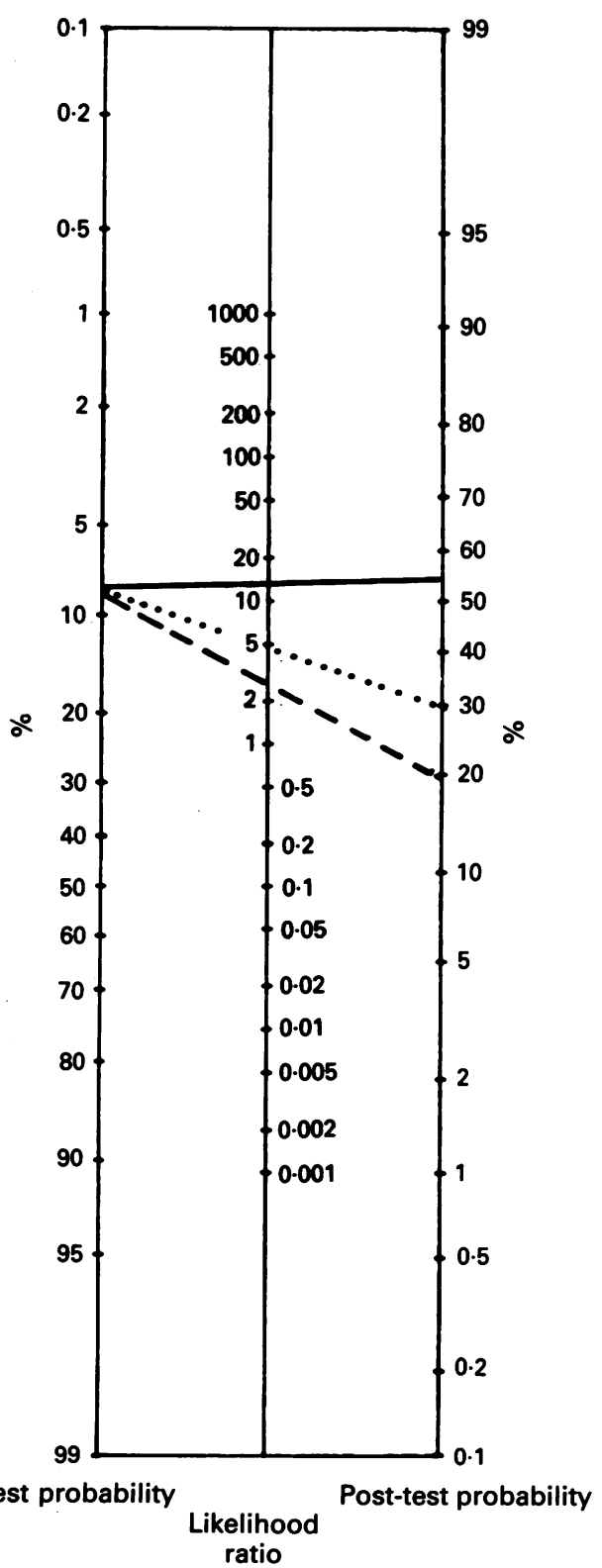

Post-test probability of Lyme arthritis at different cutoff levels in patients with unclassified arthritis after application of likelihood ratios (pretest probability 9\%). Likelihood ratio ranks 3 and $4,12 \cdot 0$ (-); likelihood ratio ranks $2-4$ 4.5 (…); likelihood ratio for arthritis of the knee, 3.0 (---). (Reprinted, by permission of the New England fournal of Medicine (1975; 293: 257).) value $(66 \%)$, and the likelihood ratio $(3.0)$ (table 4). This likelihood ratio was associated with a post-test probability of Lyme borreliosis of $20 \%$ (figure).

As only nine of the 102 patients with unclassified arthritis had positive Lyme serology, the serological test can be regarded as unnecessary in 93 patients $(91 \%)$. If antibodies to $B$ burgdorferi had been determined in the 15 patients with rank numbers 3 and 4 only, the test would have been unnecessarily ordered in only nine patients. This implies that the number of requested tests for antibodies to $B$ burgdorferi would be decreased from 102 to 15 -that is, a decrease of $86 \%$. This would have been at the expense of the three patients with rank numbers 1 and 2 who were also positive for antibodies to $B$ burgdorferi (table 2). These three patients are clinically believed to have a low probability of Lyme arthritis.

Antibodies to $B$ burgdorferi were determined in 41 patients with arthritis of the knee; six were positive for these antibodies. Therefore the test was unnecessarily ordered in 35 patients $(85 \%)$. Five of six patients with arthritis of the knee and positive for antibodies to $B$ burgdorferi were placed in ranks 3 and 4 . If requests for antibodies to $B$ burgdorferi had been made for patients with arthritis of the knee with rank numbers 3 and 4 , requests could have been decreased from 41 to five $(88 \%)$ at the expense of one patient with rank number 2 .

\section{Discussion}

This study indicates that signs and symptoms of the clinical history of a patient with arthritis are important tools to predict the chances of a positive test for antibodies to $B$ burgdorferi. Patients who clinically were expected to have a high probability of positive antibodies to $B$ burgdorferi had a post-test probability of Lyme borreliosis of $55 \%$ (based on serological test results). It is often difficult to decide at what post-test probability the diagnostic process should be stopped and treatment should be started, and at which level a working diagnosis can be rejected. ${ }^{13}$ In the clinical situation there is currently no other widely available test to increase the post-test probability of Lyme borreliosis. Culturing of the Lyme spirochaetes, especially from synovial fluid, is difficult and time consuming. ${ }^{15}$ The clinical value of Western blotting, cell mediated immunity testing, urine antigen testing, and the polymerase chain reaction still have to be determined. In the meantime, it is up to the clinician to decide whether a post-test probability of a disease of, say, $50 \%$ is sufficiently supportive to start treatment in a patient with arthritis. If the clinical history in a patient with arthritis is likely to be Lyme borreliosis (in our study patients with rank numbers 3 and 4), the chances of having Lyme borreliosis are about 55\%. This degree of suspicion is probably high enough to justify starting treatment with antibiotics in a patient with arthritis, especially because the first choice treatment with doxycycline by mouth is 
Table 5 Sensitivities, specificities, predictive values, number of tests performed, and the appropriateness of antibiotic treatment for four strategies in 102 patients with unclassified arthritis. Positive Lyme serology among 102 patients with unclassified arthritis is taken as the gold standard for the disease

\begin{tabular}{|c|c|c|c|c|c|c|c|}
\hline & \multirow[t]{2}{*}{$\begin{array}{l}\text { Sensitivity } \\
(\%)\end{array}$} & \multirow[t]{2}{*}{$\begin{array}{l}\text { Specificity } \\
(\%)\end{array}$} & \multirow[t]{2}{*}{$\begin{array}{l}\text { Positive } \\
\text { predictive } \\
\text { value (\%) }\end{array}$} & \multicolumn{2}{|c|}{$\begin{array}{l}\text { Tests } \\
\text { performed }\end{array}$} & \multicolumn{2}{|c|}{$\begin{array}{l}\text { Antibiotic } \\
\text { treatment } \\
\text { justified }\end{array}$} \\
\hline & & & & Positive & Negative & Yes & No \\
\hline Strategy $(a)^{\star}$ & 100 & 0 & 9 & - & - & 9 & 93 \\
\hline Strategy $(b)$ & 67 & 90 & 40 & - & - & 6 & $9+$ \\
\hline Strategy $(c)$ & 100 & 100 & 100 & 9 & 93 & 9 & 0 \\
\hline Strategy $(d)$ & 67 & 90 & 40 & 6 & 9 & 6 & $0+$ \\
\hline
\end{tabular}

*See text for definition of each strategy.

tAt the expense of three patients in ranks 1 and 2 .

simple and usually has only minor side effects. $^{4}$

Determination of antibodies to $B$ burgdorferi in patients with unclassified arthritis can only be considered useful when it has direct therapeutic consequences - that is, subsequent antibiotic treatment. Four different strategies will now be discussed: (a) all patients with unclassified arthritis are to receive antibiotic treatment, serological tests are not needed; $(b)$ only patients with a high suspicion of Lyme borreliosis (rank numbers 3 and 4) are to receive antibiotic treatment, serological tests are not needed; $(c)$ tests for antibodies to $B$ burgdorferi are requested for all patients with unclassified arthritis and, subsequently, the patients positive for antibodies to $B$ burgdorferi are treated with antibiotics; and $(d)$ antibodies to $B$ burgdorferi are requested only for patients with rank numbers 3 and 4 and, subsequently, the patients positive for antibodies to $B$ burgdorferi are treated with antibiotics. These four strategies have immediate consequences for the appropriateness of treatment with antibiotics and for the request for tests for antibodies to $B$ burgdorferi, as shown in table 5 . Strategy $(a)$ leads to the unnecessary treatment with antibiotics of 93 patients $(91 \%)$. Strategy (b) decreases treatment with antibiotics to 15 patients, but leads to unnecessary treatment in nine patients, and three patients from ranks 1 and 2 are not diagnosed as having Lyme arthritis and do not receive treatment with antibiotics. In strategy (c) 93 tests for antibodies to $B$ burgdorferi are requested unnecessarily. None of the patients receives unnecessary treatment with antibiotics. Strategy $(d)$ leads to a decrease of serological tests from 93 to 15 . None of the patients will be treated wrongly; however, three patients will be missed and will not receive treatment with antibiotics. Comparing strategies $(a)$ and $(c)$, testing of 102 patients could have avoided unnecessary treatment for 93 patients. Reduction of the tests performed in strategy $(d)$ avoids unnecessary treatment completely, but at the expense of the three patients with rank numbers 1 and 2 .

Several issues must be addressed with regard to our findings. There is no real 'gold standard' for Lyme borreliosis. Lyme borreliosis is primarily defined by clinical evidence, and serological results may only support this evidence. ${ }^{69}$ It is necessary to evaluate the clinical signs and symptoms of patients who are suspected to have Lyme disease carefully. Clinical evidence should outweigh serological results. Therefore it would be realised that the three patients positive for antibodies to $B$ burgdorferi who are clinically considered to have a low probability of Lyme arthritis (rank numbers 1 and 2) may in fact be asymptomatic. This would be the case if they have been infected by borrelia strains at some time in the past giving rise to the development of specific antibodies and if their arthritis was not due to Lyme borreliosis but to another (as yet unknown) cause. Asymptomatic infection with $B$ burgdorferi (positive antibodies but no clinical disease) has been found in $3-20 \%$ of healthy subjects. ${ }^{6}{ }^{16}$ The prevalence of asymptomatic infection correlates roughly with the degree of exposure. ${ }^{6}{ }^{12}$ Secondly, if likelihood ratios are to be applied in clinical practice, the doctor must have a reasonable estimate of the probability for Lyme borreliosis in the patient. This implies that prevalence data should be available. Prevalence data for Lyme arthritis in patients with unclassified arthritis are available for two different parts of the Netherlands. ${ }^{3}$ These prevalence data can probably be extrapolated to other parts of the Netherlands. We feel that the calculated likelihood ratios can be transported to patients with unclassified arthritis in a setting comparable with ours. Thirdly, our intention was to point out that clinical findings should guide the decision to select a serological test. If the doctor is convinced that a patient with arthritis has Lyme arthritis, the patient should be treated appropriately, independently of the serological test result. Unfortunately, the clinical history and symptoms are not always clear and the doctor may feel that he or she needs more support for the diagnosis. We have tried to elucidate for which patients the serological Lyme test should be selected to improve the appropriateness and efficiency.

In conclusion, in patients with unclassified arthritis clinical data are highly associated with the likelihood of a positive test for antibodies to $B$ burgdorferi. Knowledge of the pretest probability of disease, extracting key elements from the patient's clinical history and the physical examination, and application of likelihood ratios can guide the decision to request tests for antibodies to $B$ burgdorferi for these patients. Such data may promote a rational and appropriate diagnosis and treatment.

Supported by a grant from the Dutch Foundation against Rheumatism

1 Steere A C. Lyme disease. $N$ Engl f Med 1989; 321: 586-96.

Steere, A C, Schoen R T, Taylor E. The clinical evolution of Lyme arthritis. Ann Intern Med 1987; 107: 725-31.

3 Blaauw A A M, Nohlmans M K E, Leffers P, Goei The $H$ van der Linden $\mathrm{Sj}$. Lyme borreliosis: a very infrequen cause of arthritis of undetermined etiology in the southern part of the Netherlands. Br $\mathcal{F}$ Reumatol 1992; 31: 401-4

4 Liu N Y, Dinerman H, Levin R E, et al. Randomized trial of doxycycline versus amoxicillin/probenecid for the treatment of Lyme arthritis: treatment of non-responders with iv penicillin or ceftriaxon [Abstract]. Arthritis Rheum 1989; 32 (suppl): S32.

5 Blaauw A A M, Nohlmans M K E, van den Berg Loonen $\mathrm{E}$, Rasker J J, van der Linden $\mathrm{Sj}$. Lyme arthritis in $E$, Rasker $J$, van der Linden $S j$. Lyme arthritis in the Netherlands: a nationwide survey among
rheumatologists. $\mathcal{F}$ Rheumatol 1991; 18: 1819-22. 
6 Blaauw A A M, Nohlmans M K E, van den Bogaard A E $\mathrm{J} \mathrm{M}$, van der Linden $\mathrm{Sj}$. Diagnostic tools in Lyme borreliosis: clinical history compared with serology. F Clin Epidemiol 1992; 11: 1229-36.

7 Szer I S, Taylor E, Steere A C. The longterm course of Lyme arthritis in children. $N$ Engl f $\mathrm{Med}$ 1991; 325: 159-63.

8 Herzer P. Lyme-Borreliose. Epidemiologie, Ätiologie, Diagnostik, Klinik und Therapie. Darmstadt: Steinkopff Diagnostik, Klinik und Therapie.

9 Rahn D W, Malawista S E. Lyme disease: recommendations for diagnosis and treatment. Ann Intern Med 1991; 114: 472-81.

10 Craft J E, Grodzicki R L, Steere A C. The antibody response in Lyme disease spirochetes. F Infect Dis 1984; 149: 789-95.

11 Barbour A G. Isolation and cultivation of Lyme disease spirochetes. Yale f Biol Med 1984; 57: 521-5.
12 Fahrer $H$, Linden van der S M, Sauvain M J, Gern L, Zhioua E, Aeschlimann A. The prevalence and incidence of clinical and asymptomatic Lyme borreliosis in population at risk. $\mathcal{F}$ Infect Dis 1991 ; 163; 305-10.

13 Sackett D L, Haynes R B, Tugwell P. The interpretation of diagnostic data. In: Sackett D L, Haynes R B, Tugwell diagnostic data. In: Sackett $\mathrm{D}$ L, Haynes $\mathrm{R}$ B, Tugwell Boston: Little, Brown, 1991: 69-152.

14 Fagan T J. Nomogram for Bayes' theorem. $N$ Engl $\mathcal{f} \mathrm{Med}$ 1975; 293: 257

15 Snydman D R, Schenkein D P, Berardi V P, Lastavica C C, Pariser K M. B burgdorferi in joint fluid in chronic Lyme arthritis. Ann Intern Med 1986; 104: 798-800.

16 Nohlmans M K E, Bogaard van den A E J M, Blaauw A A M, Boven van C P A. Prevalentie van Lyme borreliosis in Nederland. Ned Tijdschr Geneeskd 1991; 135: 2288-92. 